\title{
Clinical Outcome Assessment Content Validation
}

National Cancer Institute

\section{Source}

National Cancer Institute. Clinical Outcome Assessment Content Validation. NCI

Thesaurus. Code C156632.

A performance outcome measure that assesses the degree of correspondence between clinical outcome assessment measures and how patients feel or function in everyday life. 